\title{
How Mobile Applications Affect Consumption in Grocery Stores
}

\author{
Anne Kokkonen \\ University of Eastern Finland \\ annekok@student.uef.fi
}

\author{
Tommi Laukkanen \\ University of Eastern Finland \\ tommi.laukkanen@uef.fi
}

\begin{abstract}
This paper examines how utilitarian and hedonic values drive customer recommendation behavior and engagement with a mobile grocery shopping application. The study further examines whether customer engagement, in terms of the usage frequency of the mobile application, influences the customer's actual spending behavior. The study tests hypothesized effects with a total sample of 541 responses from users of a mobile grocery shopping application, and among sub-samples of gender and three generational groups. The results show that the usage frequency of the mobile application has a statistically significant positive effect on money spent on the retail chain. The results further indicate gender and generational differences in the role that perceived value plays in customers' recommendation behavior and engagement with mobile grocery shopping applications.
\end{abstract}

\section{Introduction}

In a number of industrial fields value-adding mobile services have become essential to gain a competitive edge in the marketplace. The growth in the number of mobile devices and the introduction of mobile applications over the last decade has changed the markets [1,2], and companies are increasingly seeking new business opportunities through mobile services [3]. The adoption of mobile services and applications for daily use has also created new opportunities for companies to build relationships with their customers and interact with them on a personal, and frequent basis across time and space $[4,5]$. In fact, mobile services have changed the direction of communication between the customer and the company in that where communication traditionally would have taken place on the company premises and would have been dependent on the customer's presence, with mobile applications companies can send information and communicate with the customer regardless of the time and place [6]. Communication has become more location and situation specific as mobile services allow a contextual content that takes into account the time and location of the customer [7].

Mobile services are, in addition to communication, an instrument for managing customer relationships [7] and collecting individual customer data [8]. By utilizing customers' personal information and purchase history, mobile service providers are able to offer customers targeted information tailored to their specific needs and preferences [9]. Data therefore enables further development of the service to meet the needs of each customer and, thus, contributes to a greater value experience [10]. Customers have also learned to expect a more personalized and faster service through the channels they like [11]. With recent advances in mobile technology, these expectations have been met and customers have a wide range of mobile services and applications available [12] that serve their needs independent of the time and place [13].

The intense competitive environment has also led grocery retailers to focus on customer-oriented service development. New strategic trends have been sought for services that support the customer's purchasing process, where mobile services play an important role [9]. Communicating with customers through their mobile devices is a desirable way of marketing because it does not require buying media, unlike conventional advertising, and further, companies do not need to sacrifice their profits on conventional advertising if mobile channels can increase the customer's purchases [4].

Besides cost savings in advertising and targeted messaging, mobile services also help grocery chains to differentiate and position themselves on the market [9]. However, Ding and Chai [14] point out that competition for customer attention and adoption of mobile services is intense, so understanding customers' perceptions is also critical for the continuity and development of services. Saarijärvi et al. [9] note that customer perceived value provides a helpful theoretical approach for the future development of mobile services because it offers information about the benefits that mobile services provide for different customers. Although understanding customer value perceptions is important, achieving customer engagement can be challenging in 
mobile services context especially. Consequently, recent research highlights the importance of postadoption behavior, such as usage frequency and loyalty [15]. Indeed, in order to be successful, a mobile service must be able to engage the users, but also to reach new users through recommendations. Thus, in addition to engagement, empirical research on recommendations in the context of mobile services requires more attention [16].

Even though mobile services and applications, including those for grocery stores, have recently become increasingly prevalent among consumers, little is known about their influence on consumer behavior in general, and the effect on actual spending in particular. Consequently, this study is based on the theory of utilitarian and hedonic values $[17,18]$ and explores how these values affect the customers' recommendation behavior and their engagement with a mobile grocery shopping application. The study further explores how the engagement with a mobile grocery shopping application predicts the customer's actual spending on the retail chain, and how this relationship varies across gender and three generations, that is millennials, generation $\mathrm{X}$, and baby boomers.

\section{Literature review and hypotheses development}

\subsection{Utilitarian and hedonic values}

Customer perceived value, also known as customer value, is central to marketing both in research and practice $[19,20]$. However, it has proved difficult to define because of the abstractness and diversity of the concept [21, 22]. Although customer perceived value has been studied much from the perspectives of psychology, sociology and economics [23], the concept involves interpretative complexity [24]. For example, Woodruff [25] has highlighted the challenge of the conceptualization because customer perceived value often refers to other concepts, such as benefits, values, and quality that are also difficult to define. Parasuraman [26] argues that in addition to defining perceived value, it is also challenging to create a scale that monitors the complexity of the phenomenon.

According to a traditional one-dimensional view, value is generated in an exchange where the customer compares the benefits offered and the sacrifices required to achieve the benefits [27]. The sacrifices required to achieve benefits may be both material and intangible [28]. Customer perceived value is personal and situational. This means that customer perceived value varies in terms of the personality, attitudes, emotions, and demographic factors of an individual [24].
Consequently, customer perceived value can be seen as an individually varying subjective experience of the positive and negative aspects regarding a product or service [25, 29].

Customer perceived value can be divided into utilitarian and hedonic values describing the instrumental and experiential goals of spending [17]. According to Hirschman and Holbrook [18], both cognitive and experiential factors must be taken into account when defining customer perceived value. They argue that defining value cannot only focus on the product, its price, or its operational benefits as the only value-generating factors, because customer perceived value is also influenced by symbolic, hedonic, and aesthetic factors. In addition to the objective factors, we must understand consumer behavior that is not only rational and fulfill the functional, physical or financial objectives, but also aims to satisfy emotional needs [17].

Some products and services are more utilitarian in nature, while others have more hedonistic aspects. However, these are not mutually exclusive but can be expressed in the same product or service with different emphasis [30]. Utilitarian values arise when a deliberate outcome is achieved through conscious activity such as purchasing a product [17]. The utilitarian perspective considers consumption as a performance [18], through which the goals set for consumption are met efficiently [17]. The utilitarian values relate to economic factors, such as product prices and functional factors such as time and effort. While, for example, financial savings and the convenience of purchasing create utilitarian value, hedonic values arise from the purchasing experience and social and symbolic factors related to the customers' ability to express themselves through consumption [39]. Babin et al. [17] argue that hedonic values are based on spontaneous behavior and are experiential and affective. They say that hedonic value derives from the excitement, fascination and escapism, for example, that purchasing creates. Indeed, the product does not necessarily act as an instrument for the creation of hedonic value, but in some cases the purchase process itself can produce hedonic value when the purchase experience or the intangible aspects of the product provide the customer with a valuable experience [32]. Thus, hedonic values are more subjective than utilitarian values, and they are more individual and more situational, including elements such as the fun and playfulness of buying [18]. Hedonic values are in themselves valuable $[17,32]$, which makes them abstract and subjective [31, 32].

Understanding both utilitarian and hedonic values is important for the success of mobile services [7]. In this study we operationalize utilitarian and hedonic values through two consumption values namely functional and emotional values [29, 33, 34, 35]. 
2.1.1. Functional value. Functional value is based on cognitive perceptions and derives from the features and attributes that the customer considers useful in satisfying functional, utilitarian and physical needs and expectations [29]. Thus, functional value stems from the practicality and usefulness of a product or service. The functional value in mobile services refers to the ability of the service to save time and effort, that is the practical features of the mobile service that facilitate and speed up processes [34]. The mobile service can be considered as an information channel [33], whereby customers can easily access new information and benefit from individual offers [5], and thus save time and money [34]. Consequently, functional value materializes when the mobile service increases the practicality of the decision making through savings in time and effort [36].

2.1.2. Emotional value. Emotional values are important for customers who appreciate the experience of buying. Emotional value consists of feelings that the product or service provide to the customer $[29,35]$ and represent the customer's mental and psychological needs [35]. Emotional value can be measured by the feelings customers associate with a particular product or service, and are combined with both tangible products and more experiential services. In the case of mobile services, the emotional value derives from the good feelings, relaxation, and satisfaction that arises in the interaction between the customer and the information obtained through the service [34]. Emotional value can also derive from the enjoyment and playfulness that the mobile service offers [33].

\subsection{Recommendation behavior}

Recommendations are one of the corner stones of the mobile services' success [16]. Customers rely more on the information shared by other customers than the information provided by companies, experts, or advertisers [37, 38]. Timmerman and Shepherd [37] note that recommendations from peers are important in acquiring knowledge about a particular mobile service. Indeed, recommendations can be considered an increasing form of viral marketing, in which customers share information on the use and characteristics of products and services [39].

Earlier research on mobile services finds that functional and emotional values have positive effects on the customers' recommendation behavior [34, 40]. Consequently, we hypothesize:

\section{$H_{1}$ : Functional value is positively associated with the recommendation of the mobile grocery shopping application.}

$\mathrm{H}_{2}$ : Emotional value is positively associated with the recommendation of the mobile grocery shopping application.

\subsection{Customer engagement}

Few mobile services are able to engage customers. Another corner stone for the success of mobile services, in addition to recommendations, is the continuous and frequent use of the service [15]. Indeed, Kim et al. [5] define customer engagement with mobile services as a repeated use of the service. They argue that customer is likely to become a service user if he or she experiences a mobile service to produce such a utilitarian or hedonic value that other media or channels are unable to provide. A number of studies suggest that utilitarian and hedonic values influence customer engagement with mobile services $[2,5]$. Thus, we hypothesize:

\section{$H_{3}$ : Functional value is positively associated with customer engagement with the mobile grocery shopping application.}

$H_{4}$ : Emotional value is positively associated with customer engagement with the mobile grocery shopping application.

Earlier research argues that customer engagement positively influences the willingness to make recommendations in the context of web pages [54]. The same phenomenon has also been observed regarding mobile services. Studies have found that the more committed a customer is to using a particular mobile service, the more likely the customer will also recommend it [16]. Consequently, we hypothesize:

\section{$H_{5}$ : Engagement with the mobile grocery shopping application is positively associated with recommendation behavior.}

\subsection{Spending behavior}

With mobile services, grocery retailers are looking to provide added value for their customers and for greater customer engagement, but also to increase customer spending and purchase volumes. This is because customer purchases of products and services contribute directly to firm value [41]. Pansari and Kumar [42] suggest that customer purchases are a direct contribution of customer engagement. Consequently, we hypothesize: 
$H_{6}$ : Customer engagement with the mobile grocery shopping application increases customer purchases in the retail chain.

\subsection{The moderating role of gender}

Gender is one of the most studied demographic characteristics in an electronic services context. Academic research has demonstrated great differences between genders in relation to perceptions and the adoption of mobile services. Earlier research, for example, argues, that when compared to women, males perceive less risk in mobile services [43] and have greater odds of using mobile services [44]. Earlier studies also claim that males tend to evaluate mobile commerce more positively than women [45]. Based on this reasoning we believe that the hypothesized relationships will vary between genders. Consequently:

\section{$H_{7}:$ Gender moderates the effects of $H_{I-6}$}

\subsection{The moderating role of the cohort}

Early marketing research shows that people of different ages vary in their inclinations toward technology-based services [46]. More recently, research has evinced major generational differences in online trust and perceived privacy concerning electronic services [47], as well as the acceptance of tablet devices [48] and mobile apps [49]. Consequently, we believe that the hypothesized relationships will vary between generational groups, often referred to as cohorts. Thus:

\section{$H_{8}:$ Cohort moderates the effects of $H_{1-6}$}

Figure 1 illustrates the theoretical model of the study.

Moderators:

H7 Gender

H8 Cohort

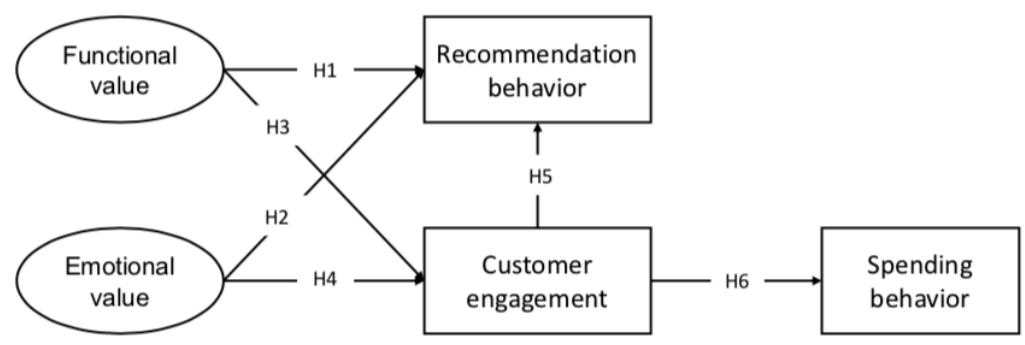

Figure 1. Conceptual model and hypotheses

\section{Data and methods}

Data for the study was collected with an online questionnaire targeted for customers of a large grocery retail chain in Finland. The survey was sent to 2010 randomly selected customers of an online community. The members of the community had pre-accepted that they could be approached with online questionnaires related to products and services of the retail chain. The survey resulted in 541 valid responses from customers who had adopted the mobile grocery shopping application of the retail chain.

The measures for functional and emotional value (Table 1) were derived from the earlier literature on customer perceived value [29, 33, 34, 35]. Specific attention was paid to using measures that evaluate the respondents' perceptions toward the mobile application per se, not the retailer.

Customer engagement was operationalized with a single item measure of usage frequency (i.e. the number of times the mobile app was used in a week), while the customer recommendation behavior was measured with the well-known Net Promoter Score NPS [50] that asks respondents to evaluate how likely they would be to recommend the application to others on a ten-point scale. Finally, the spending behavior was operationalized with an individual-level measure of the amount (EUR) spent on monthly purchases made in the retail chain. 
Table 1. Measures of the latent constructs

\begin{tabular}{l} 
Latent \\
constructs \\
\hline Functional value \\
1 The mobile application speeds up the shopping \\
in store. \\
2 The mobile application eases shopping \\
planning. \\
3 Using this mobile application allows me to plan \\
shopping at a convenient time for me. \\
4 The mobile application helps me to save money. \\
Emotional value \\
1 Using this mobile application makes me feel \\
good. \\
2 Using this mobile application is fun. \\
3 The mobile application inspires me. \\
4 I enjoy using the mobile application. \\
5 I feel that the mobile application knows me as a \\
consumer.
\end{tabular}

The gender and cohort (generational group) served as moderators in the study. The data is female dominated with $349(64.5 \%)$ and $192(35.5 \%)$ female and male respondents respectively. As for the cohort, we divided the sample into three generational groups, namely: millennials (19-35 years), generation X (36-55 years), and baby boomers ( $>55$ years) (Table 2$)$.

Table 2. Sample distribution

\begin{tabular}{lrr}
\hline Item & $\mathbf{N}$ & $\%$ \\
\hline Gender & & \\
Female & 349 & 64.5 \\
$\quad$ Male & 192 & 35.5 \\
Cohort & & \\
$\quad$ Millennials & 114 & 21.1 \\
Generation X & 298 & 55.1 \\
$\quad$ Baby boomers & 129 & 23.8 \\
Total & 541 & 100.0 \\
\hline
\end{tabular}

We used confirmatory factor analysis (CFA) to validate the two latent constructs, i.e. functional value and emotional value. In addition, we conducted a multigroup invariance analysis to ensure that the measurement model yielded an equal representation between the moderation groups. Thereafter, we tested the hypotheses with three structural models: a baseline model for testing $H_{1-6}$ with the full sample, and two multigroup models to test $H_{7}$ and $H_{8}$.

\section{Construct validation}

A CFA model for the two latent constructs with nine observed variables indicated a good fit to the data with $\chi 2 / \mathrm{df}=3.154, \mathrm{CFI}=0.983$, RMSEA $=0.063$ (Table $3)$.
Table 3. Reliability estimates

\begin{tabular}{lccc}
\hline $\begin{array}{l}\text { Latent } \\
\text { constructs }\end{array}$ & Item & Alpha & $\begin{array}{c}\text { Factor } \\
\text { loadings }\end{array}$ \\
\hline Functional value & & 0.848 & 0.770 \\
& 1 & & 0.891 \\
& 2 & & 0.841 \\
Emotional value & 3 & & 0.584 \\
& 1 & 0.917 & \\
& 2 & & 0.824 \\
& 3 & & 0.871 \\
& 4 & & 0.863 \\
& 5 & & 0.896 \\
\hline
\end{tabular}

Note: All the factor loadings are significant at $\mathrm{p}<0.001$

To assess the discriminant validity the average variance extracted (AVE) for the two latent constructs was compared to the squared correlation of the constructs (Table 4). Discriminant validity was supported as the AVE values were greater than the squared correlation of the constructs [51]. Moreover, both the AVE values and the composite reliability (CR) values supported convergent validity.

\section{Table 4. Discriminant validity}

\begin{tabular}{lcccc}
\hline Construct & AVE & CR & $\mathbf{1}$ & $\mathbf{2}$ \\
\hline 1. Functional value & 0.609 & 0.859 & $\mathbf{0 . 6 0 9}$ & \\
2. Emotional value & 0.695 & 0.919 & 0.472 & $\mathbf{0 . 6 9 5}$ \\
\hline
\end{tabular}

Thereafter, a series of multigroup invariance tests were conducted using the AMOS 25 software package. In the first stage, the configural invariance was tested. This means testing that the same basic factor structure exists in all the moderation groups studied [52]. Thus, we created a model which tests for the validity of the factorial structure simultaneously across the moderation groups. This model provides a value against which all the later specified models of the invariance test are compared [53].

As for the gender moderator, goodness-of-fit statistics showed a chi-square value of $122.49(d f=52)$ and fit indices of CFI $=0.979$, and RMSEA $=0.050$ indicating a good fit across the two groups. All the factor loadings for all measure items were highly significant at the $p<0.001$ level in both female and male segments. Thus, the model showed configural invariance across gender. Similarly, the goodness-of-fit statistics showed a good fit across the three generational groups (cohort) with a chi-square value of $155.22(d f=78)$ and fit indices of $\mathrm{CFI}=0.977$, and RMSEA $=0.043$, indicating configural invariance. Both moderators also supported full metric invariance and full factor variance invariance as the models (gender: $\Delta \chi^{2}(7)=1.29, p>0.05 ; \Delta \chi^{2}{ }_{(9)}=5.48$, $\mathrm{p}>0.05$; cohort: $\Delta \chi^{2}{ }_{(14)}=13.60, \mathrm{p}>0.05 ; \Delta \chi^{2}\left({ }_{18}=17.06\right.$, 
$\mathrm{p}>0.05$ ) are not significantly poorer than the fit of the configural invariance models. This shows complete model invariance between gender and cohort (Table 5).

\section{Results}

\subsection{Baseline model}

The results of the path analysis of the overall model with the full sample show that both the functional and emotional values have a statistically significant effect on consumer recommendation behavior with $\beta=0.21$ $(\mathrm{p}<0.001)$ and $\beta=0.46(\mathrm{p}<0.001)$ respectively, and on customer engagement with $\beta=0.25(\mathrm{p}<0.001)$ and $\beta=0.24(\mathrm{p}<0.001)$ respectively. Thus, the results support $\mathrm{H}_{1-4}$.

The results also support the positive effect of customer engagement on recommendation behavior $(\beta=0.19 ; \mathrm{p}<0.001)$ and on customer spending behavior $(\beta=0.23 ; \mathrm{p}<0.001)$ supporting $\mathrm{H}_{5}$ and $\mathrm{H}_{6}$ (Figure 2).

Table 5. Measurement invariance tests

\begin{tabular}{|c|c|c|c|c|c|c|c|c|}
\hline \multirow[b]{2}{*}{ Model tested (Gender) } & \multicolumn{5}{|c|}{ Model fit measures } & \multicolumn{3}{|c|}{ Model differences } \\
\hline & $\mathrm{x}^{2}$ & df & $\mathrm{X}^{2} / \mathrm{df}$ & CFI & RMSEA & $\Delta \mathbf{X}^{2}$ & $\Delta \mathbf{d f}$ & Sig. \\
\hline 1 Configural invariance & 122.49 & 52 & 2.356 & 0.979 & 0.050 & & & \\
\hline 2 Full metric invariance & 123.78 & 59 & 2.098 & 0.980 & 0.045 & 1.29 & 7 & ns. \\
\hline 3 Full factor variance invariance & 127.97 & 61 & 2.098 & 0.980 & 0.045 & 5.48 & 9 & ns. \\
\hline Model tested (Cohort) & $x^{2}$ & df & $\mathrm{X}^{2} / \mathrm{df}$ & $\mathrm{CFI}$ & RMSEA & $\Delta \mathbf{X}^{2}$ & $\overline{\Delta \mathbf{d f}}$ & Sig. \\
\hline 1 Configural invariance & 155.22 & 78 & 1.990 & 0.977 & 0.043 & & & \\
\hline 2 Full metric invariance & 168.82 & 92 & 1.835 & 0.977 & 0.039 & 13.60 & 14 & ns. \\
\hline 3 Full factor variance invariance & 172.28 & 96 & 1.795 & 0.977 & 0.038 & 17.06 & 18 & ns. \\
\hline
\end{tabular}

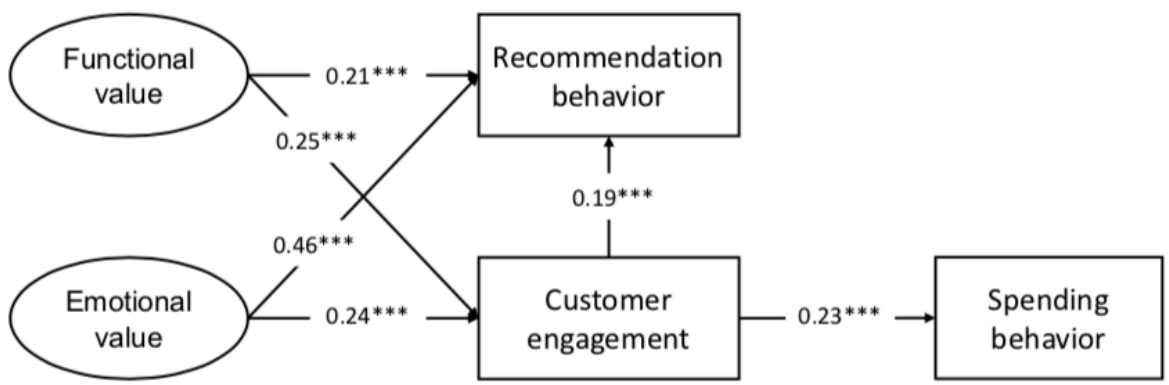

Note: ${ }^{* * *}=p<0.001 ; n s=$ not significant

\section{Figure 2. Path estimates of the baseline model}

\subsection{The moderating role of gender}

Earlier research suggests that gender plays a role in consumer attitudes toward innovations and that these attitudes are likely to affect consumer behavior. The results of this study indicate that functional and emotional values related to a mobile grocery shopping application have different effects on the recommendation behavior and customer engagement. The results show that the perceived functional value increased recommendations more among males than among females with $\beta=0.45(\mathrm{p}<0.001)$ and $\beta=0.14$ $(\mathrm{p}<0.05)$ respectively. However, it appears that the emotional value attached to the mobile grocery shopping application enhanced the customer engagement (i.e. usage frequency) of the application among females $(\beta=0.27 ; \mathrm{p}<0.001)$, but not among males $\left(\beta=0.17 ; \mathrm{p}=\mathrm{ns}\right.$.). The results lend support to $\mathrm{H}_{7}$ (Table 6).

\subsection{The moderating role of the cohort}

Both, the academic literature and general discussion related to cohort argue that great behavioral differences exist between different generational groups. According to the results of this study, functional value did not drive recommendation behavior among millennials $(\beta=-0.03 ; \mathrm{p}=\mathrm{ns}$.), but emotional value has a statistically highly significant effect $(\beta=0.44$; 
$\mathrm{p}<0.001)$. However, perceived functional value had a significant effect on customer engagement $(\beta=0.33$; $\mathrm{p}<0.05$ ), but the effect of emotional value is not significant $(\beta=0.08 ; \mathrm{p}=\mathrm{ns}$.). While among generation $\mathrm{X}$ the effects of functional and emotional value on recommendation behavior and customer engagement are all highly significant. Furthermore, functional value does not increase customer engagement among the baby boomers $(\beta=0.09 ; \mathrm{p}=\mathrm{ns}$. $)$. Consequently, the results support $\mathrm{H}_{8}$ (Table 7).

Table 6. Results of the multigroup analysis across genders

\begin{tabular}{llrrrr}
\hline Paths & \multicolumn{4}{c}{ Female } & \multicolumn{1}{c}{ Male } \\
\cline { 2 - 6 } & & Estimate & Sig. $(\boldsymbol{p})$ & Estimate & Sig. $(\boldsymbol{p})$ \\
\cline { 2 - 6 } Functional value & $\rightarrow$ Rec. behavior & 0.142 & $<0.05$ & 0.454 & $<0.001$ \\
Emotional value & $\rightarrow$ Rec. behavior & 0.495 & $<0.001$ & 0.300 & $<0.001$ \\
Functional value & $\rightarrow$ Cust. engagement & 0.228 & $<0.01$ & 0.340 & $<0.01$ \\
Emotional value & $\rightarrow$ Cust. engagement & 0.268 & $<0.001$ & 0.168 & Ns. \\
Cust. engagement & $\rightarrow$ Rec. behavior & $0.231<0.001$ & 0.110 & $<0.05$ \\
Cust. engagement & $\rightarrow$ Spending behavior & 0.184 & $<0.001$ & 0.296 & $<0.001$ \\
\hline Note: ns = not significant
\end{tabular}

Note: $\mathrm{ns}=$ not significant

Table 7. Results of the multigroup analysis across cohorts

\begin{tabular}{|c|c|c|c|c|c|c|c|}
\hline \multirow[t]{2}{*}{ Paths } & & \multicolumn{2}{|c|}{ Millennials } & \multicolumn{2}{|c|}{ Generation X } & \multicolumn{2}{|c|}{ Baby boomers } \\
\hline & & Estimate & Sig. $(p)$ & Estimate & Sig. (p) & Estimate & Sig. $(p)$ \\
\hline Functional value & $\rightarrow$ Rec. behavior & -0.031 & Ns. & 0.272 & $<0.001$ & 0.284 & $<0.01$ \\
\hline Emotional value & $\rightarrow$ Rec. behavior & 0.662 & $<0.001$ & 0.437 & $<0.001$ & 0.347 & $<0.01$ \\
\hline Functional value & $\rightarrow$ Cust engagement & 0.327 & $<0.05$ & 0.273 & $<0.001$ & 0.089 & Ns. \\
\hline Emotional value & $\rightarrow$ Cust. engagement & 0.081 & Ns. & 0.269 & $<0.001$ & 0.414 & $<0.01$ \\
\hline Cust. engagement & $\rightarrow$ Rec. behavior & 0.269 & $<0.001$ & 0.132 & $<0.01$ & 0.278 & $<0.001$ \\
\hline Cust. engagement & $\rightarrow$ Spending behavior & 0.184 & $<0.05$ & 0.214 & $<0.001$ & 0.343 & $<0.001$ \\
\hline
\end{tabular}

Note: $\mathrm{ns}=$ not significant

\section{Conclusions}

This paper examined the role of utilitarian and hedonic values on customer recommendation behavior and customer engagement with a mobile grocery shopping application. The study further examined whether customer engagement with the mobile application influenced the customer's spending behavior. These effects were tested with an overall sample of 541 users of a mobile grocery shopping application, and among sub-samples of gender and three generational groups.

We measured utilitarian and hedonic values with the constructs of functional value and emotional value derived from the earlier literature. Customer recommendation behavior refers to the Net Promoter Score that is a single value item measured on a ten-point scale indicating a respondent's likelihood to recommend the mobile application to others, while customer engagement refers to the number of times the respondent uses the mobile app in a week. Finally, spending behavior is the monthly purchase volume (EUR) of the customer in the retail chain.

The study found that customer engagement with the mobile grocery shopping application increased customer spending, and the results show that the more a customer used the application, the more (s)he spent in the retail chain. This is supported by Wang et al. [4] who found that as customers adapt to the mobile technology offered by a retail company and incorporate the mobile technology as a part of their habitual behavior, they develop a habit of interacting with the firm and increase their spending behavior.

The study further found that the functional and emotional value attached to the mobile grocery shopping application had significant effects on the usage frequency of the application and on the likelihood of recommending the application to others. However, the results indicate that functional value is a more important indicator for recommendations among males, while emotional value attached to the application increased the usage frequency among females, but not among males. Consequently, it seems that while males put more emphasis on the functional aspects of the mobile application, the emotional aspects drove the behavior of females. In addition, it seems that while both functional and emotional value supported recommendation behavior in general, the millennials' recommendation behavior was tied to the emotional value attached to the mobile application, and functional value did not have an effect. However, the case was the opposite with regards to engagement. It seems that the perceived functional value increased the usage frequency among millennials, while emotional value did not have a significant effect. Again, this is reversed among the baby boomers whose 
emotional value attached to the mobile application supported an increase in the usage frequency of the application, while functional value did not.

Utilitarian and hedonic values also deserve further attention in the context of mobile services, especially among the millennials. This study confirms the general discussions that millennials, indeed, appear to be a clearly distinct segment when it comes to online and mobile behavior. Studies concentrating on the differences between millennials and other generational segments are needed to better respond to the divergent needs of these obviously dissimilar groups of consumers. Moreover, the root reasons for the differences found in this study need to be examined. Therefore, we recommend researchers to take a qualitative approach, for example, to gain an in-depth understanding of the role utilitarian and hedonic values play in mobile grocery shopping.

\section{References}

[1] A. Persaud and I. Azhar, "Innovative mobile marketing via smartphones", Marketing Intelligence \& Planning, (30:4), 2012, pp. 418-443.

[2] C. Xu, D. Peak, and V. Prybutok, "A customer value, satisfaction, and loyalty perspective of mobile application recommendations", Decision Support Systems, (79), 2015, pp. 171-183.

[3] M.R. Islam, M.R. Islam, and T.A. Mazumder, "Mobile application and its global impact", International Journal of Engineering \& Technology, (10:6), 2010, pp. 72-78.

[4] R.J-H. Wang, E.C. Malthouse, and L. Krishnamurthi, "On the Go: How Mobile Shopping Affects Customer Purchase Behavior", Journal of Retailing, (91), 2015, pp. 217-234.

[5] S.J. Kim, R. Wang, and E.C. Malthouse, E.C., "The Effects of Adopting and Using a Brand's Mobile Application on Customers' Subsequent Purchase Behavior", Journal of Interactive Marketing, (31), 2015, pp. $28-41$.

[6] V. Shankar, A. Venkatesh, C. Hofacker, and P. Naik, "Mobile Marketing in the Retailing Environment: Current Insights and Future Research Avenues", "Journal of Interactive Marketing”, (24), 2010, pp. 111-120.

[7] V. Shankar, M. Kleijnen, S. Ramanathan, R. Rizley, S. Holland, and S. Morissey S., "Mobile Shopper Marketing: Key Issues, Current Insights, and Future Research Avenues", Journal of Interactive Marketing, (34), 2016, pp. 37-48.

[8] T. Lee, T. and J. Jun, J., "Contextual perceived value? Investigating the role of contextual marketing for customer relationship management in a mobile commerce context", Business Process Management Journal, (13:6), 2007, pp. 798-814.

[9] H. Saarijärvi, L. Mitronen, and M. Yrjölä, "From selling to supporting - Leveraging mobile services in the context of food retailing", Journal of Retailing and Consumer Services, (21), 2014, pp. 26-36.

[10] R. Ström, M. Vendel, and J. Bredican, "Mobile marketing: A literature review on its value for consumers and retailers", Journal of Retailing and Consumer Services, (21:6), 2014, pp. 1001-1012.

[11] H.B. Corrigan, G. Craclun, and A.M. Powell, "How Does Target Know So Much About Its Customers? Utilizing Customer Analytics to Make Marketing Decisions", Marketing Education Review, (24:2), 2014, pp. 159-166.

[12] Y.H. Kim, D.J. Kim, and K. Wachter, "A study of mobile user engagement (MoEN): Engagement motivations, perceived value, satisfaction, and continued engagement intention", Decision Support Systems, (56), 2013, pp. 361-370.

[13] K. Varnali, K. and A. Toker, "Mobile marketing research: The-state-of-the-art", International Journal of Information Management, (30), 2010, pp. 144-151.

[14] Y. Ding, Y. and K.H. Chai, "Emotions and continued usage of mobile applications", Industrial Management \& Data Systems, (115:5), 2015, pp. 833-852.

[15] C. Chou, C. Chiu, C. Ho, and J. Lee, "Understanding mobile apps continuance usage behavior and habit: an expectance-corfirmation theory", PACIS 2013 Proceedings, 2013, p. 132.

[16] S. Kim, T.H. Baek, Y-K. Kim, and K. Yoo, "Factors affecting stickiness and word of mouth in mobile applications". Journal of Research in Interactive Marketing", (10:3), 2016, pp. 177-192.

[17] B. Babin, W. Darden, and M. Griffin, "Work and/or fun: Measuring hedonic and utilitarian shopping", Journal of Consumer Research, (20:4), 1994, pp. 644-656.

[18] E.C. Hirschman, and M.B. Holbrook, "Hedonic Consumption: Emerging Concepts, Methods and Propositions", Journal of Marketing, (46), 1982, pp. 92101.

[19] J.C. Sweeney, G.N. Soutar, and L.W. Johnson, "The role of perceived risk in the quality-value relationship: A study in a retail environment", Journal of Retailing, (75:1), 1999, pp. 77-105.

[20] J.B. Smith, and M. Colgate, "Customer Value Creation: A Practical Framework". Journal of Marketing Theory and Practice, (15:1), 2007, pp. 7-23. 
[21] R. Sánchez-Fernández, and M.Á. Iniesta-Bonillo, “The concept of perceived value: A systematic review of the research”. Marketing Theory, (7:4), 2007, pp. 427-451.

[22] M.G. Gallarza, R. Gil-Saura, and M.B. Holbrook, "The value of value: Further excursions on the meaning and role of customer value", Journal of Consumer Behaviour, (10), 2011, pp. 179-191.

[23] P.E. Boksberger, and L. Melsen, "Perceived value: a critical examination of definitions, concepts and measures for the service industry", Journal of Services Marketing, (25:3), 2011, pp. 229-240.

[24]F. Huber, A. Hermann, and R.E. Morgan, "Gaining competitive advantage through customer value oriented management", Journal of Consumer Marketing, (18:1), 2001, pp. 41-53.

[25] R.B. Woodruff, "Customer value: The next source for competitive advantage", Journal of the Academy of Marketing Science, (25:2), 1997, pp. 139-153.

[26] A. Parasuraman, "Reflections on gaining competitive advantage through customer value". Journal of the Academy of Marketing Science, (25:2), 1997, pp. 154161.

[27] V.A. Zeithaml, "Consumer perceptions of price, quality, and value: A means-end model and synthesis of evidence", Journal of Marketing, (52:3), 1988, pp. 2-22.

[28] A. Parasuraman, and D. Grewal, "The impact of technology on the quality-value-loyalty chain: a research agenda", Journal of the Academy of Marketing Science, (28:1), 2000, pp. 168-174.

[29] J.N. Sheth, B.I. Newman, and B.L. Gross, "Why we buy what we buy: A theory of consumption values", Journal of Business Research, (22), 1991, pp. 159-170.

[30] R. Batra, R. and O.T. Ahtola, "Measuring the hedonic and utilitarian sources of consumer attitudes", Marketing Letters, (2:2), 1990, pp. 159-170.

[31] T. Rintamäki, and K. Kirves, "From perceptions to propositions: Profiling customer value across retail contexts", Journal of Retailing and Consumer Services, (37), 2017, pp. 159-167.

[32] T. Rintamäki, A. Kanto, H. Kuusela, and M.T. Spence, "Decomposing the value of department store shopping into utilitarian, hedonic and social dimensions", International Journal of Retail \& Distribution Management, (34:1), 2006, pp. 6-24

[33] H. Wang, C. Liao, and L. Yang. "What affects mobile application use? The roles of consumption values", International Journal of Marketing Studies, (5:2), 2013, pp. 11-22.
[34] M. Pihlström, G.J. Brush, "Comparing the perceived value of information and entertainment mobile services", Psychology and Marketing, (25:8), 2008, pp. 732-755.

[35] J.C. Sweeney, and G.N. Soutar, "Consumer perceived value: The development of a multiple item scale", Journal of Retailing, (77), 2001, pp. 203-220.

[36] H. Yang, and R. Lin, "Determinants of the intention to continue use SoLoMo services: Consumption values and the moderating effects of overloads", Computers in Human Behavior, (73), 2017, pp. 583-595.

[37] J.E. Timmerman, and I. Shepherd, "Does eWOM affect demand for mobile device applications?", Journal of Marketing Development and Competitiveness, (10:3), 2016, pp. 9-16.

[38] Y-F. Kuo, T-L. Hu, and S-C. Yang, "Effects of inertia and satisfaction in female online shoppers on repeat purchase intention: The moderating roles of word-ofmouth and alternative attraction", Managing Service Quality: An International Journal, (23:3), 2013, pp. 168187.

[39] F. Li, and T.C. Du, "Who is talking? An ontology-based opinion leader identification framework for word-ofmouth marketing in online social blogs", Decision Support Systems, (51), 2010, pp. 190-197.

[40] J-Y.M. Kang, and K.K.P. Johnson, "Positive word-ofmouth for mobile location-based service retail apps usage", International Journal of Mobile Communications, (13:6), 2015, pp. 599-618.

[41] S. Gupta, D.R. Lehmann, and J.A. Stuart, "Valuing customers", Journal of Marketing Research, (41:1), 2004, pp. 7-18.

[42] A. Pansari, V. Kumar, "Customer engagement: the construct, antecedents, and consequences", Journal of the Academy of Marketing Science, (45), 2017, pp. 294-311.

[43] H. Nysveen, P.E. Pedersen, H. Thorbjørnsen, "Intentions to Use Mobile Services: Antecendents and Cross-Service Comparisons", Journal of the Academy of Marketing Science, (33:3), 2005, pp. 330-343.

[44] T. Laukkanen, "Consumer adoption versus rejection decisions in seemingly similar service innovations: The case of the internet and mobile banking", Journal of Business Research, (69:7), 2016, pp. 2432-2439.

[45] K. Yang, "Exploring factors affecting the adoption of mobile commerce in Singapore", Telematics and Informatics, (22:3), 2005, pp. 257-277.

[46] M. Gilly and V. Zeithaml, "The Elderly Consumer and Adoption of Technologies", Journal of Consumer Research, (12:December), 1985, pp. 353-357. 
[47] M. Obal, and W. Kunz, "Trust development in e-services: a cohort analysis of Millennials and Baby Boomers", Journal of Service Management, (24:1), 2013, pp. 45-63.

[48] K Magsamen-Conrad, S. Upadhyaya, S., C.Y. Joa, and J. Dowd, "Bridging the divide: Using UTAUT to predict multigenerational tablet adoption practices", Computers in Human Behavior, (50), 2015, pp. 186-196.

[49] H.J. Hur, H.K. Lee, H.J. Choo, "Understanding usage intention in innovative mobile app service: Comparison between millennial and mature consumers", Computers in Human Behavior, (73), 2017, pp. 353-361.

[50] F.F. Reichheld, "The one number you need to grow", Harvard Business Review, (81:12), 2003, pp. 46-55.

[51] C. Fornell and F.D. Larcker, "Evaluating structural equation models with unobservable variables and measurement error", Journal of Marketing Research, (18:1), 1981, pp. 39-50.

[52] J.F. Hair, W.C. Black, B.J. Babin, R.E. Anderson, Multivariate Data Analysis, 7th edition, Prentice Hall, Upper Saddle River, New Jersey, 2010.

[53] B.M. Byrne, "Testing for multigroup invariance using AMOS Graphics: A road less travelled", Structural Equation Modeling: A Multidisciplinary Journal, (11:2), 2004, pp. 272-300.

[54] S.K. Roy, W.M. Lassar, and G.T. Butaney, "The mediating impact of stickiness and loyalty on word-ofmouth promotion of retail websites: A consumer perspective", European Journal of Marketing, (48:9), 2014, pp. 1828-1849. 